$\begin{array}{cc}\text { Türk Coğrafya Dergisi } & \text { Turkish Geographical Review } \\ \text { Basıli ISSN 1302-5856 } & \text { ww.tcd.org.tr }\end{array}$

\title{
1925 yılında Isparta vilayetinde konar-göçerlerin iskanı
}

\section{The Settlement of nomads in Isparta province in 1925}

\author{
Illker Yiğit *a \\ ${ }^{a}$ Burdur Mehmet Akif Ersoy Üniversitesi, Fen-Edebiyat Fakültesi, Coğrafya Bölümü, Burdur.
}

ORCID: I.Y. 0000-0002-1473-3438

\begin{tabular}{|c|c|}
\hline BİLGi / INFO & ÖZ / ABSTRACT \\
\hline $\begin{array}{l}\text { Geliş/Received: } 16.03 .2020 \\
\text { Kabul/Accepted: } 10.08 .2020\end{array}$ & $\begin{array}{l}\text { XI. yüzyıldan itibaren yoğun Türk akının başladığı Anadolu topraklarına yerleşik hayat benimsemiş } \\
\text { olan köylü ve şehirlilerin yanında konar-göçer gruplar da gelmiştir. Anadolu’ya geldikten sonra söz } \\
\text { konusu gruplardan bir kısmı zaman içerisinde yerleşik hayat benimserken bir kısmı ise yaylak ve }\end{array}$ \\
\hline $\begin{array}{l}\text { Anahtar Kelimeler: } \\
\text { Tarihi coğrafya } \\
\text { iskan } \\
\text { yaylak } \\
\text { kışlak } \\
\text { yörük }\end{array}$ & $\begin{array}{l}\text { kışlak mekanları arasındaki faaliyetlerine devam etmişlerdir. XVII. yüzyıldan itibaren devlet eliyle } \\
\text { konar-göçerler iskan edilmeye çalışıldı ise de bunun tam manasıyla başarılı olmadığı görülmekte- } \\
\text { dir. Zira Osmanlının son dönemlerinde ve hatta Cumhuriyet devrinde konar-göçer grupları iskan } \\
\text { çalışmaları devam etmiştir. Bu araştırmada da Cumhuriyet'in ilk yıllarında Isparta çevresini yaylak, } \\
\text { Antalya çevresini de kışlak olarak kullanan konar-göçerlerin Isparta vilayeti dahiline yerleştirilme- } \\
\text { leri arşiv vesikaları üzerinden ele alınmıştr. Bu sahada bulunan konar-göçerlere yer gösterilmek } \\
\text { ve arazi tahsis edilmek suretiyle Eğirdir kazasına Karakoyunlu (200 kişi), Töngüşlü ( } 50 \text { kişi), Eski }\end{array}$ \\
\hline $\begin{array}{l}\text { Keywords: } \\
\text { Historical geography } \\
\text { settlement } \\
\text { summer pastures } \\
\text { winter pastures } \\
\text { yoruk }\end{array}$ & $\begin{array}{l}\text { Yörük ( } 50 \text { kişi), Çakal (108 kişi) ve Honamlı ( } 83 \text { kişi); Uluborlu kazasına Honamlı (464 kişi), Karako- } \\
\text { yunlu ( } 342 \text { kişi) ve Saçıkaralı (188 kişi); Karaağaç kazasına Karakoyunlu (103 kişi), Hayta ( } 83 \text { kişi) ve } \\
\text { Saçıkaralı ( } 25 \text { kişi); Isparta kazasına Saçıkaralı ( } 21 \text { kişi); Yalvaç kazasına Saçıkaralı (183 kişi) aşireti } \\
\text { iskan edilmiştir. Konar-göçerlerin kaza, nahiye, köy, çftlik, yayla gibi yerleşmelerin yanı sıra çeşitli } \\
\text { mevkilere de iskan edildiği görülmektedir. }\end{array}$ \\
\hline
\end{tabular}

*Sorumlu yazar/Corresponding author:

(i. Yiğit)

iyigithg@gmail.com

DOI: $10.17211 /$ tcd. 704770

As of the 11th century, there were peasants and nomadic groups who came to the villages and townspeople who had settled in the Anatolian lands where intensive Turkish influx began. After coming to Anatolia, some of the groups in question adopted the settled life over time, while some continued their activities between. Although it was tried to be settled by the state since the summer pastures and winter pastures the 17th century, it is seen that this is not completely successful. Because the settlement of the nomad groups in the last period of the Ottoman Empire and even during the Republican period continued. In this study, the placement of the nomads, which use the Isparta environment as summer pasture and the Antalya environment as a winter pasture, in the first years of the Republic, was discussed through archive documents. By giving place to the nomads in this field and allocating land, the Eğirdir district Karakoyunlu (200 people), Töngüşlü (50 people), Eski Yörük (50 people), Çakal (108 people) and Honamlı (83 people); 464 people), Karakoyunlu (342 people), and Saçıkaralı (188 people); Karaağaç district Karakoyunlu (103 people), Hayta (83 people) and Saçıkaralı (25 people); Isparta district Saçıkaralı (21 people); The tribe of Saçıkaralı (183 people) was settled in Yalvaç district. It is seen that nomads settled in various locations as well as settlements such as district, sub-districts, villages, farms and summer pastures.

Attf/Citation:
Yiğit, İ. (2020). 1925 yılında Isparta vilayetinde konar-göçerlerin iskanı. Türk Coğrafya Dergisi (75), 33-40.

DOI: $10.17211 /$ tcd. 704770

\section{Extended Abstract Introduction}

As of the 11th century, along with the villagers and city dwellers who adopted the settled life, settlers and nomadic groups came to the Anatolian lands where the intense Turkish influx started. After coming to Anatolia, some of the groups in question have adopted settled life over time, while others have continued their activities between the summer pastures and winter pastures. It is understood that nomads are also engaged in agricultural activities at a certain level in their area. Apart from agricultural activities, nomads were mainly meeting the meat and milk needs of the state and the need for 
horse breeding. Apart from these, they performed important services by fulfilling certain obligations such as transporting state (miri) property, working in mines, repairing and maintaining roads and bridges in return for a certain exemption.

Nomadic groups of nomads occasionally disturbed the settled inhabitants while going to and from the summer pastures and winter pastures. There have been cases such as damage by animals to the agricultural lands of the settled inhabitants, grabbing of crops and animals, and even destruction of settlements in some cases. For these and similar reasons, the Ottoman Empire attempted to settle the nomadic tribes, which performed important functions during the establishment and development periods, after a certain period. In the Ottoman period, the settlement works of nomads started in the 17th century and continued in the 18th and 19th centuries. However, although it was tried to be settled by the state since the 17 th century, it is seen that this was not successful in the full sense. Because, in the last periods of the Ottoman Empire and even in the Republican era, the settlement activities of nomadic groups continued. With the settlement of nomadic groups, the problems of the settled inhabitants would be eliminated, some banditry activities would be prevented, a serious population mass would be attached to a specific place, making agricultural production under the hands of the state, paying taxes and ultimately contributing to the country's economy. At the same time, many empty and dilapidated lands would thus become operational economically.

In the 19th century, the "İskan-ı Muhacirin Komisyonu(Immigration Commission)" was established for the settlement of immigrants who came to the Ottoman lands. In time, an Immigration Commission was established in each province and linked to the "Umum Müdürlüğü (General Directorate)", headquartered in Istanbul. It is seen that the organization of this General Directorate was reorganized by taking the name "Aşair ve Muhacirin Müdüriyet-i Umumiyesi (General Directorate of Tribes and Refugees)" according to the organization law enacted in 1914. While the directorate was initially established only to deal with immigrants, it has also undertaken the settlement of nomadic tribes in the process.

\section{Data and Method}

It is seen that various studies have been carried out by disciplines such as geography, history and sociology regarding nomadic communities. It is noteworthy that many studies have been carried out by geographers regarding transhumance, which has an important place in Turkish culture. At this point, researches on nomads by geography scientists; It is seen that field research is in the form of an evaluation of the related literature, which refers to this issue among general studies. In this research, the settlement of nomads in Isparta province, who used Isparta as a plateau and the vicinity of Antalya as a winter pasture in the first years of the Republic, was discussed through archive documents. The archive document, which was prepared for the settlement of nomads in the first years of the Republic and includes information about the plateau and winter quarters of the tribes subject to settlement, their population, settlement areas, the amount of land allocated and the nature of the land, constituted the main source of the research. Along with this archive document, there is a map showing the settlements where nomads were inhabited. Within the scope of the information and findings obtained from the archive documents, various maps were made and efforts were made for a better understanding of the subject. First of all, the localization of the centres where the tribes were inhabited was made and after that, various thematic maps were created in the Arc-Gis 10.4 (Arc-Map) program, depending on the need. In the study, based on the information contained in the archive document, the tribes' settlement areas, their populations, the amount of land allocated and the nature of the land were discussed within the province of Isparta.

\section{Results and Discussion}

It is understood that the settlement works of nomads, which started in the 17th century during the Ottoman Empire, continued in the Republic period as well. It can be said that the state prefers the settled state that it can easily access and control, as well as the damage they cause to the environment as a result of various banditry activities in the settlement of nomads. During the settlement of nomadic tribes, the state took care to allocate land and agricultural land for permanent settlement by establishing various commissions. It is seen that these lands are empty and abandoned in Isparta province.

Karakoyunlu, Töngüşlü, Eski Yörük, Çakal, Honamlı in the table-lands of Eğirdir district; Karaağaç district (in Çayır locality) Karakoyunlu; Hayta and Saçıkaralı tribes were resettled in the table-lands of the Karaağaç district. These tribes were settled in Eğirdir, Uluborlu, Karaağaç, Yalvaç and Isparta towns. As a result of the study carried out in Isparta province in 1925, 1005 people in 201 tents/households in the table-lands of Eğirdir district; 80 tents/households were settled in the Karaağaç district Karaağaç district (in Çayır locality), and 500 people in 100 tents/households in the Karaağaç district table-lands.

By giving place to the nomads in this field and allocating land, the Eğirdir district Karakoyunlu (200 people), Töngüşlü (50 people), Eski Yörük (50 people), Çakal (108 people) and Honamlı (83 people); 464 people), Karakoyunlu (342 people), and Saçıkaralı (188 people); Karaağaç district Karakoyunlu (103 people), Hayta (83 people) and Saçıkaralı (25 people); Isparta district Saçıkaralı (21 people); The tribe of Saçıkaralı (183 people) was settled in Yalvaç district. It is seen that nomads settled in various locations as well as settlements such as district, sub-districts, villages, farms and summer pastures.

\section{Giriş}

Osmanlı toplumu inanç durumuna göre Müslim ve gayrimüslim olmak üzere temelde ikiye ayrılabilmelerinin yanı sıra iktisadi faaliyetleri ve yaşayış tarzlarına göre de farklı tasnifler yapmak mümkündür. Osmanlı nüfusunun büyük çoğunluğu şehir, kasaba ve köylerde yerleşik halde bulunurken yerleşik halkın dışında nüfusun önemli bir kısmını da konar-göçer gruplar teşkil ediyordu (Şahin, 1999: 132). Osmanlı Devleti, halkının iktisadi faaliyetlerinin sürekliliğini önemseyerek buna göre çeşitli uygulamalar geliştirilmesi yolunda izlediği politikaların bir yansıması olarak, konar-göçer topluluklarla ilgili birtakım iyileştirmeler yapmak, tedbirler almak suretiyle onları ekonominin bir parçası haline getirmiştir (Gündüz, 2016a: 20). 
Arşiv vesikalarında aşiret, cemaat, oymak şeklinde tanımlanan konar-göçerlerin, bulundukları bölgeye ve yaşayış biçimlerine göre "Türk/Etrak", "Yörük" veya "Türkmen" gibi isimlerle nitelendiği görülür. Bölgeden bölgeye belirli isimlendirme tercih ediliyor olsa da aynı bölge içinde bir konar-göçer grubu ifade etmek amacıyla kavramların birbiri yerine (örneğin Yörük ve Türkmen gibi) kullanılabildiği anlaşılmaktadır (Büyükcan Sayılır, 2013: 24).Anadolu'nun batısında XVII. yüzyıldan önce konar-göçerlik edenlere ve bunların kurduğu köylere "Yörük köyü", XVII. yüzyıldan sonra söz konusu sahalara gelen konar-göçerlere de "Türkmen", kurdukları köylere de "Türkmen köyü" denilmek suretiyle isimlendirildiği görülmektedir (Gündüz, 2016b: 54).

Tarihi süreç içerisinde konar-göçer teşekküller, yapı itibariyle değişik gruplar halinde bulunabilmektedir. Bunlar; a) Bir boydan ibaret olan -tek başına ve- müstakil bir teşekkül halinde bulunan konar-göçerler. b) Bir boydan ayrılmış ve zamanla çoğalarak sayıları dörtten on altiya hatta daha fazla bir sayıya ulaşabilen oymaklar grubu. c) Federasyon şekli gösteren konar-göçer kuruluşlar (Orhonlu, 1987: 14-16) şeklinde sıralanabilir.

Konar-göçerler gruplar sosyal ve ekonomik sistem açısından timarlı reaya statüsünde bulunuyorlardı. Yaylak ve kışlak dahilinde timar veya vakıf arazisinde aynen timarlı reaya gibi ürettikleri ürünler üzerinden vergilerini ödüyorlardı (Tabakoğlu, 1999: 29). Konar-göçerler tarımsal faaliyetlerin dışında, esasen devletin et ve süt ihtiyacına, at yetiştiriciliğine duyulan gereksinimine cevap veriyorlardı. Bunların dışında belirli bir muafiyet karşılığında miri malı taşımak, maden ocaklarında çalışmak, yol ve köprüleri onarmak/korumak gibi birtakım yükümlülükleri de yerine getirerek önemli hizmetler icra ediyorlardı (Saydam, 1999: 182). Hal böyle olunca Osmanlı devlet ve toplum yapısının ayrılmaz bir parçasını konar-göçer teşekküller meydana getiriyordu (Inalcık, 2000: 75).

Osmanlı İmparatorluğu kuruluş ve gelişme dönemlerinde önemli fonksiyonlar icra eden konar-göçer aşiretleri, belirli bir zaman sonra yerleştirme girişimlerinde bulunmuştur. Konar-göçerlerin iskan çalışmaları XVII. yüzyılda başlamış olup XVIII. ve XIX. yüzyılda da devam etmiştir. Bu süreçte konar-göçerlerin harap ve boş arazilere yerleştirilmeye gayret edildiği görülmekte olup söz konusu girişimlerin temel hedefleri şöyle sıralanabilir: a) Başıboş konar-göçer toplulukların eşkıyalıklarını önlemek ve yerleşik halka yönelik zararları sona erdirmek. b) Boş ve harap yerleri imar ederek şenlendirmek ve tarıma açmak. c) Yeni mamureler kurmaktır (Halaçoğlu, 1999: 584).

Konar-göçerler gruplar, yaylak ve kışlak mekânlarına gidip gelirken zaman zaman yerleşik ahaliyi rahatsı etmişlerdir. Yerleşik ahaliye ait tarım arazilerinin hayvanlara çiğnetilmesi, mahsullerin ve hayvanların gasp edilmesi, hatta bazı durumlarda yerleşmelerin tahrip edilmesi gibi durumlar söz konusu olmuştur. Çoban ile saban arasında bir mücadele olarak nitelenebilecek bu süreç, konar-göçer kitlelerin lehine sonuçlanmıştur (Orhonlu, 1987: 39-42; Halaçoğlu, 2014: 43-50).

Konar-göçer grupların iskân edilmesiyle, yerleşik ahalinin sıkıntıları ortadan kalkacak, birtakım eşkıyalık faaliyetlerinin önüne geçilecek, ciddi bir nüfus kitlesi belirli bir mekâna bağlanarak devletin elinin altında zirai üretim yapacak, vergisini ödeyecek ve en nihayetinde ülke ekonomisine katkı sağlayacakt. Aynı zamanda boş ve harap halde bulunan birçok arazi böylece ekonomik manada işlerlik kazanacakt (Yiğit, 2018: 381). Konar-göçer toplulukların yerleşik hayata geçmesinin dönem belgelerinde "Türkmenlikten çıkt", "Yörüklükten çıkt" şeklinde ifade edildiği anlaşılmaktadır. Nitekim Ayas, Kınık ve Berendi kazalarına yerleşen konar-göçerler, arşiv vesikasına “... ifrâz-ı Zülkadiriye reayası fimâ-ba'd Türkmenlikten çıkıp Ayas ma'a Berendi ve Kınık kazalarında sâkin olup..." şeklinde yansımıştır (Gündüz, 2016b: 56).

XVII. yüzyılda başlayan konar-göçerleri iskan girişimleri XVIII. yüzyılda da devam etmiş ancak söz konusu girişimlerin başarıSı sınırlı olmuştur (Egawa ve Şahin, 2007: 112; Gündüz, 2002: 163). XIX. yüzyılın başında bazı bölgelerde konar-göçerlerin sayısındaki artış bu bağlamda dikkate değer veriler olarak değerlendirilebilir. Örneğin Adana vilayetinde Tanzimat'ın hemen öncesinde 56955 konar-göçere karşın 5000 yerleşik köylü bulunmaktadır. Uç bir örnek olarak değerlendirilebilirse dahi asırlardır devam eden konar-göçerleri iskan çalışmalarının başarı oranının düşük kaldığının bir göstergesi olarak bu veriler önemli bir ipucu teşkil etmektedir (Kasaba, 2012: 107-108). İskan politikalarının başarıya ulaşmamasının nedenleri arasında iskan mahallerinin coğrafi özelliklerine dikkat edilmemiş olması, konar-göçerlerin hayat tarzlarına uygun yerlerin verilmemiş olması, tarım için verilen toprakların verimsiz olması, konar-göçerlerin hayat tarzlarının yöneticiler tarafindan tam olarak anlaşılamamış olması gibi durumlar belirtilmektedir (Doğan, 2007: 142).

Tanzimat dönemiyle birlikte konar-göçer toplulukların bulundukları eyaletlerin dışına çıkmalarına sınırlamalar getirilmiştir. Bu bağlamda 1842 yılına gelindiğinde yaylak-kışlak hususunda ortaya çıkan karışıkııların ortadan kaldırılması amacıyla aşiretlerin bulundukları sancak ve kaza dahilinde kalmaları istenmiştir. Konar-göçerlerin hali ve terk edilmiş araziler üzerinde iskanı ve tarımsal üretime geçmeleri için çalışmalar yürütülmüştür (Halaçoğlu, 1999: 585). Köy idaresinin teşkili ve Arazi Kanunnamesi ile ülke dahilindeki arazilerin önce kadastrosuz olarak da olsa parsellenmesi, konar-göçerlerin geleneksel yaylak ve kışlak mahallerinin köy arazileri içinde kalmasına yol açmıştır. Bu durum konar-göçerleri zor durumda bırakmış ve yerleşik hayata icbar eden bir hususiyet taşımıştır (Aydın ve Yağcı, 2013: 61-62).

Osmanlı topraklarına gelen göçmenlerin iskanı için XIX. yüzyılda "İskan-ı Muhacirin Komisyonu" kurulmuştur. Zaman içinde her vilayette birer İskan-ı Muhacirin Müdürlüğü tesis edilerek, merkezi İstanbul'da olan Umum Müdürlüğü'ne bağlanmıştır. Bu Umum Müdürlüğü’nün teşkilat 1914'te çıkan teşkilat kanununa göre "Aşair ve Muhacirin Müdüriyet-i Umumiyesi" ismini alarak yeniden düzenlendiği görülmektedir. Bu haliyle müdüriyet önceleri sadece göçmenlerle ilgili olmak üzere teşkil edilmişken süreç içerisinde konar-göçer aşiretlerin yerleştirilmesi işini de üstlenmiştir (Orhonlu, 1987: 119-120).

Konar-göçer topluluklara ilişkin olarak coğrafya, tarih, sosyoloji gibi disiplinler tarafindan çeşitli araştırmaların gerçekleştirilmiş olduğu görülmektedir. Türk kültüründe önemli bir yeri 
olan yaylacılık faaliyeti ile ilgili olarak coğrafyacılar tarafindan birçok çalışmalar yapıldığı dikkati çekmektedir Bu noktada coğrafya bilim mensupları tarafindan konar-göçerlere ilişkin araştırmalar; alan araştırması, genel çalışmalar içerisinde bu konuya değinen ve ilgili alan yazının değerlendirmesi şeklinde olduğu görülmektedir (Tunçel, 2015: 6). Eldeki bu çalışmada ise arşiv kaynakları kullanılarak Isparta vilayetine iskan edilen konar-göçer aşiretler tarihi coğrafya bağlamında ele alınarak değerlendirilmeye gayret edilmiştir.

\section{Veri ve Yöntem}

Çalışmada da 1925 yılı Isparta vilayeti örnekleminde konar-göçerlerin iskan süreci, tarihi coğrafya açısından ele alınmıştır. Cumhuriyet'in ilk yıllarında konar-göçerlerin iskanı ile ilgili olarak hazırlanan ve iskana konu olan aşiretlerin yaylak ve kışlak alanları, nüfusları, iskan mahalleri, tahsis edilen arazi miktarları ile arazinin mahiyetini dair bilgiler içeren arşiv vesikası (Cumhurbaşkanlığı Devlet Arşivleri Başkanlığı Cumhuriyet Arşivi, 272.0.0.65.6.3.7) araşttrmanın temel kaynağını oluşturmuştur. Bu arşiv vesikası ile beraber bir de konar göçerlerin iskan edildiği yerleşmeleri gösteren harita mevcuttur. Arşiv belgelerinden elde edilen bilgi ve bulgular dahilinde çeşitli haritalar yapılarak konunun daha iyi anlaşması için gayret sarf edilmiştir. Öncelikle aşiretlerin iskan edildiği merkezlerin lokalizasyonu yapılmış ve bundan sonra da ihtiyaca binaen Arc-Gis 10.4 (Arc-Map) programında çeşitli tematik haritalar oluşturulmuştur. Çalışmada arşiv vesikasında yer alan bilgilerden hareket edilerek aşiretlerin iskan mahalleri, nüfusları, tahsis edilen arazi miktarları ve arazinin mahiyeti Isparta vilayeti kazaları dahilinde ele alınmıştır.

\section{Bulgular ve Tartışma}

\subsection{Isparta Vilayetinde Konar-Göçerlerin İskanı (1925)}

Konar-göçerler kanunnamelerde "Yörüklerin muayyen karargâhı olmayıp eyyam-ı sayfiyede yaylaklara çıkıp, kış eyyamında ............ kışlarlar" şeklinde tanımlanmaktadır (Gülten, 2016: 50). Belgelerde de açıkça belirtildiği üzere yaylak ile kışlak arasında dönemlik bir harekete sahip olan konar-göçerlerin zaman içinde devlet tarafindan iskan edilmesine karar verilmiştir. Bu süreçte özellikle yerleşik ahaliye ve onların iktisadi düzenlerine zarar vermeleri, eşkıyalıkta bulunmaları gibi durumların belirleyici olduğu anlaşılmaktadır. Ayrıca devletin ahalisini belirli bir alanda kontrol altında tutma ve yönetme arzusunun da bu durumun ortaya çıkmasında etkili olduğu söylenilebilir.

Isparta çevresindeki konar-göçerlerin Osmanlı zamanından itibaren birtakım eşkıyalık faaliyetlerine karıştı̆ı ve tarihi süreç içerisinde devleti meşgul eden birtakım hususlara yol açthğı görülmektedir. Konar-göçerleri yerleştirme teşebbüsleri kapsamında, 6 Aralık 1718 tarihinde Hamid sancağındaki bazı konar-göçer toplulukların iskan alanlarını terk ederek firar ettikleri bilgisi dönem belgelerine yansımıştır. İskan mahallerini terk edenlerin yerlerine getirilmesi için emirler gönderilmiştir. Ayrıca bazı konar-göçer toplulukların eşkıyalık faaliyetlerine karıştı̆ı ve yerleşik ahaliyi bezdirdikleri 1734 tarihli fermanda yer almaktadır. Antalya ve Serik çevrelerinden yaylak için Hamid sancağına gelen konar-göçer topluluklar (Gebüz, Alaylı, Firkatlı, Serikli, ve Kesirli cemaatleri) yerleşik durumda olan halkın tarım arazilerine zarar vermelerinin ötesinde hırsızlık, mala ve mülke karşı suçlar işlemişler ve hatta cinayetle sonuçlanan durumların ortaya çıkmasına yol açmışlardır. Bu suçlarına binaen 20.000 guruş nezri ödemeyen bahse konu konar-göçer gruplardan tahsilatın gerçekleştirilmesi, ödemeyenlerin sürgün edilerek uygun mahallere iskan edilmeleri yönünde fermanlar çıkarılmıştır (Akdemir, 2008: 116-119). Hamid-ili çevresindeki konar-göçer toplulukların XVIII. yüzyıldaki durumunu gösteren bu örnekler devletin söz konusu topluluklarla olan meşguliyetine dair önemli fikirler vermektedir.

Isparta çevresinde çeşitli arşiv vesikaları ve çalışmalardan anlaşıldığını göre konar-göçer topluluklar hep var olmuştur. Antalya ve Serik çevrelerinde kışı geçiren konar-göçer topluluklar yaz mevsiminde Isparta çevresindeki yaylalara gelmişlerdir.

Konya Vilayet Salnamesi'nde (1914 tarihli) Eğirdir kazasında Sorkun, Senitli, Keşli, Çayır, Camili, Sanlı, Zengi, Kuzukulağı isimlerinde yaylaların mevcut olduğu ve yaylak için Antalya çevresinden 10000 'inin üzerinde çadır halkı geldiği belirtildikten sonra Gebiz, Saçıkaralu, Karakoyunlu, Honamlı, Horzum, Eskiyörük, Hayta, Çakal, Sarıkeçili aşiretlerinin isimleri sayılmaktadır. Aynı salnamede Karaağaç (bugün Şarkikaraağaç) çevresi için Akbel, Üçkuyu, Söbüova, Kocalan, Akarca, Çayağzı yaylaları sayılmakta Antalya vs. yerlerden 4000-5000 çadırdan oluşan hane halkları ile Karakoyunlu, Eskiyörük, Karahacılı, Töngüşlü, Fettahlı, Saçıkaralı, Hacıisalu, Hayta, Sarıkeçili aşiretlerinin bu bölgede yazı geçirdikleri belirtilmiştir (Ak, 2018: 3).

30 Aralık 1898 tarihinde başlayıp 6 Mayıs 1915 yılında tamamladığı Isparta Tarihi isimli eserinde Böcüzâde Süleyman Sami, sancak dahilinde "Millü, Sarı Keçili, Saçı karalı, Kara hacılı, Horzumlu, Tüngüşlü, Eski Yörük, Honamlı, Karakoyunlu, Fettahlı namlarında ve daha saîr namlarda birtakım cemaatler" olduğunu belirtmiştir. i̇lgili eserde konar-göçer toplulukların kış aylarını Antalya civarında, yaz aylarını ise Isparta sancağında geçirdikleri ifade edilmiştir (Babacan, 2012: 107).

Besim Zühdü tarafindan kaleme alınan 1922 yılına ait Türkiye'nin Sıhh-i ve İçtimai Coğrafyası, Hamidabad (Isparta) Sancağı isimli eserde Hamid-ili çevresinde bulunan Antalya sahilini kışlak Isparta çevresini de yaylak olarak kullanan konar-göçer gruplar arasında Saçıkaralı (175 çadır/1400 kişi), Karakoyunlu (180 çadır/1440 kişi), Sarıkeçili (100 çadır/800 kişi), Eski Yörük (90 çadır/720 kişi), Fettahlı (15 çadır/400 kişi), Gebiz (40 çadır/320 kişi), Karatekeli (20 çadır/160 kişi), Aksığırlı (15 çadır/20 kişi) aşiretleri sayılmaktadır (Babacan ve Temurçin, 2013:20-21).

Osmanlı İmparatorluğu'nu asırlarca meşgul eden konar-göçerlerin iskanı Cumhuriyet Türkiye'sinin de temel meselelerinden birini oluşturmuştur. Osmanlının son zamanlarında tesis edilen komisyonların raporları doğrultusunda Türkiye Büyük Millet Meclisi'nde 3 Mart 1925'te konar-göçer aşiretlerin Dahiliye Vekaleti bünyesinde olmak üzere iskan edilmeleri kabul görmüştür. Çıkarılan iskan kanunu ile birlikte konar-göçer aşiretlerin yerleşik hale getirilmelerine ilişkin çalışmalara başlanmıştır. Bu dönemde bazı aşiretler kendi rızaları ile devlete müracaat ederek yerleşme taleplerini iletmişler ve tercih ettikleri bölgelere iskan edilmişlerdir (Erdal, 2008: 5; Erdal, 2016: 112). 
Eldeki araştırmanın temel kaynağını oluşturan, 10 Kanun-ı evvel 1341 (14 Aralık 1925) tarihinde düzenlenmiş olan arşiv vesikasında, Isparta vilayetine iskan edilecek aşiretlerin durumu şöyle ifade edilmiştir: "Isparta vilayetine, Antalya vilayetiyle Akşehir ve civarından yaz mevsiminde gelerek kışın 'avdet eden 'aşâir-i seyyârenin bulundukları mıntkkalarla iskan edilecekleri mevâkı-ı gösterir cedveldir". Verilen bu metinden de anlaşıldığı üzere iskana konu edilen aşiretlerin kış mevsiminde Antalya çevresini kışlak, yaz mevsiminde ise Isparta çevresini yaylak olarak kullandıkları anlaşılmaktadır. Bu durum yukarıda verilen bilgiler de göz önüne alındığında sahadaki konar-göçerlerin asırlardır sürdüre geldikleri faaliyetleri aynı yaylak ve kışlak mahallini kullanmak suretiyle devam ettirdiklerini gözler önüne sermektedir.

Isparta vilayeti dahilinde iskan edilen aşiretler arasında Eğirdir kazası yaylalarında Karakoyunlu, Töngüşlü, Eski Yörük, Çakal, Honamlı; Karaağaç kazası Çayır mevkiinde Karakoyunlu; Karaağaç kazası yaylalarında Hayta, Saçıkaralı aşiretleri bulunmaktadır (Şekil 1).
Eğirdir kazası yaylalarında 201 çadır/hane de 1005 kişi; Karaağaç kazası Çayır mevkiinde 80 çadır/hane de 450 kişi, Karaağaç kazası yaylalarında ise 100 çadır/hane de 500 kişinin iskana tabi tutulmuştur. Aşiretlerin Antalya nüfusuna kayıtlı oldukları ve kışı Antalya çevresinde geçirdiklerine ilişkin notlar arşiv vesikasında her bir kaza için ayrı ayrı yazılmak suretiyle belirtilmiştir. Aşağıda bahse konu aşiretler, iskan edildikleri mahallere göre ele alınarak değerlendirilecektir.

\subsubsection{Eğirdir kazasına iskan edilen konar-göçer topluluklar}

Eğirdir kazasına iskan edilen konar-göçer topluluklar Karakoyunlu, Töngüşlü, Eski Yörük, Çakal ve Honamlı aşiretlerinden oluşmaktadır. Karakoyunlu aşireti Eğirdir kazası Cebel nahiyesi Bavullu yaylası ve Zengi yaylasına (40 çadır/hane de 200 kişi), Töngüşlü aşireti Eğirdir kazası Melekler köyüne (10 çadır/hane de 50 kişi), Eski Yörük aşireti Eğridir kazası Barla nahiyesi Belbel ve Akkeçili mevkilerine (10 çadır/hane de 50 kişi), Çakal aşireti Eğirdir kaza merkezine (22 çadır/hane de 108 kişi), Honamlı aşireti Eğirdir kazası Barla nahiye merkezine (16 çadır/ hane de 83 kişi) iskan edilmiştir.

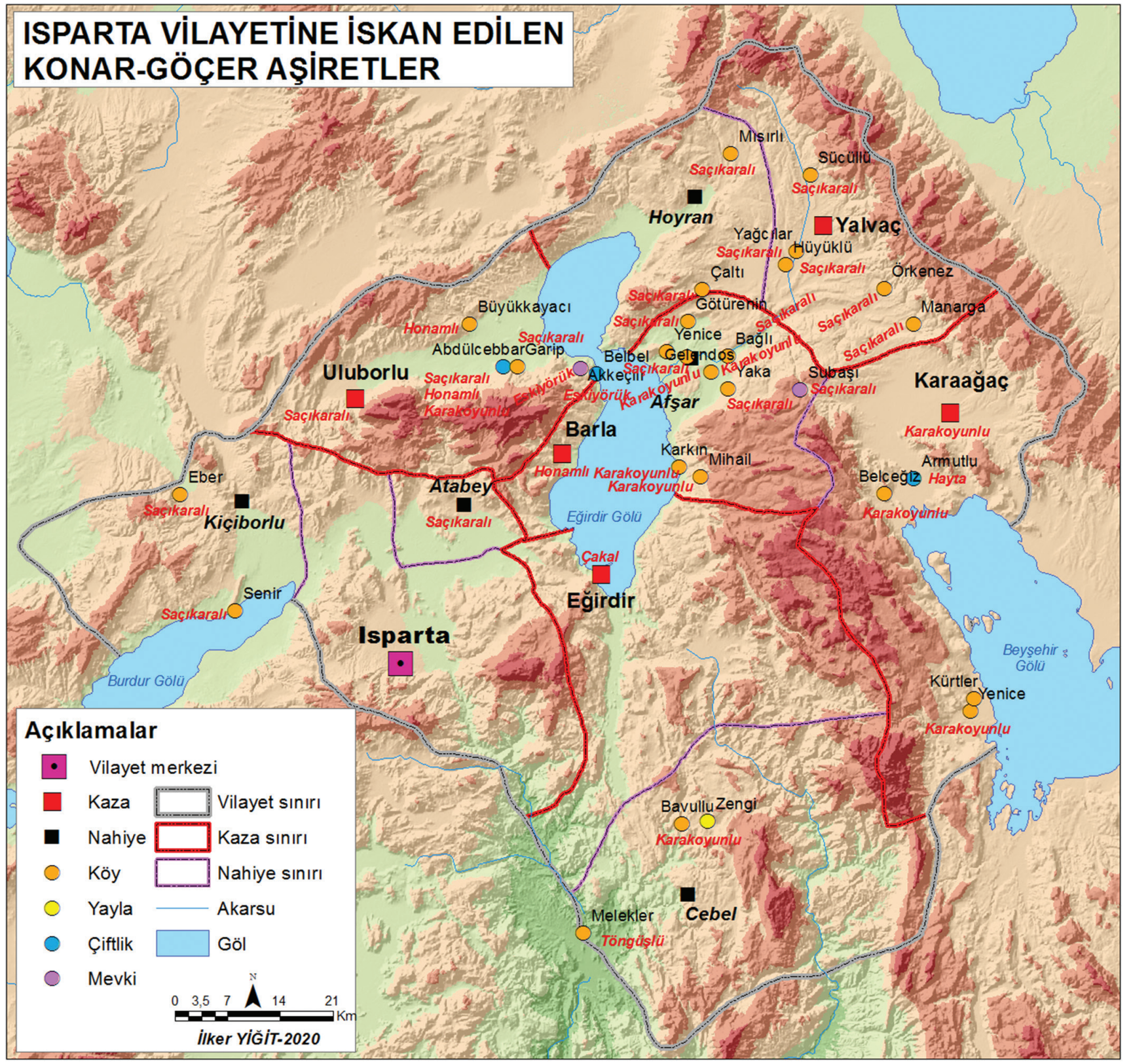

Şekil 1. Isparta Vilayetine İskan Edilen Konar-Göçer Aşiretler

Figure 1. Nomadic Tribes Settled in Isparta Province 
Cebel nahiyesine iskân edilen 40 çadır/hane de 1005 kişiden oluşan Karakoyunlu aşiretine Bavullu ve Zengi yaylasında 2000 dönüm hali arazi (sahibi olmayan boş arazi); Melekler köyüne iskan edilen 20 çadır/hane de 100 kişiden oluşan Töngüşlü aşiretine 1000 dönüm hali arazi; Barla nahiyesi Belbel ve Akkeçili mevkilerine iskan edilen 10 çadır/hane de 50 kişiden oluşan Eski Yörük aşiretine 500 dönüm hali arazi, Eğirdir kaza merkezine iskan edilen 22 çadır/hane de 108 kişiden oluşan Çakal aşiretine Rum mübadillerinden kalan 1080 dönüm arazi, Barla nahiyesi merkezine iskan edilen 16 çadır/hane de 83 kişiden oluşan Honamlı aşiretine Rum mübadillerinden kalan 289 dönüm arazi tahsis edilmiştir.

\subsubsection{Uluborlu kazasına iskan edilen konar-göçer topluluklar}

Uluborlu kazasına iskan edilen konar-göçer topluluklar Honamlı, Karakoyunlu ve Saçıkaralı aşiretlerine mensuptur. Honamlı aşiretinden 63 çadır/hane de 312 kişi Uluborlu kazası Büyük Kayacı köyüne ve 20 çadır/hane de 152 kişi de Uluborlu kazası Abdülcebbar çiftliğine iskan edilmiştir. Karakoyunlu aşiretinden 61 çadır/hane de 342 kişi Uluborlu kazası Abdülcebbar çiftliğine iskan edilmiştir. Saçıkaralı aşiretinden Uluborlu kazası merkezine 3 çadır/hane de 15 kişi, Uluborlu kazası Garip köyüne 2 çadır/hane de 9 kişi, Uluborlu kazası Abdülcebbar çiftliğine 32 çadır/hane de 164 kişi iskan edilmiştir.

Uluborlu kazası Büyük Kayacı köyüne iskan edilen 63 çadır/ hane de 312 kişiden oluşan Honamlı aşiretine 3210 dönüm hali arazi, Uluborlu kazası Abdülcebbar çiftliğine iskan edilen 20 çadır/hane de 152 kişiden oluşan Honamlı aşiretine 1520 dönüm mahlul arazi(Araziyi kullanan kişinin ölümü neticesinde varisi olmadığından devlete kalan arazi bkz. Gültekin, Tarihsiz: 3), Uluborlu kazası Abdülcebbar çiftliğine iskan edilen 61 çadır/hane de 342 kişiden oluşan Karakoyunlu aşiretine 3480 dönüm mahlul arazi, Uluborlu kaza merkezine iskan edilen 3 çadır/hane de 15 kişiden oluşan Saçıkaralı aşiretine Rum mübadillerinden kalan 147,5 dönüm arazi, Uluborlu kazası Garib köyüne iskan edilen 2 çadır/hane de 9 kişiden oluşan SaçıkaraIı aşiretine 84 dönüm hali arazi, Uluborlu kazası Abdülcebbar çiftliğine iskan edilen 32 çadır/hane de 164 kişiden oluşan Saçıkaralı aşiretine 1600 dönüm hali arazi tahsis edilmiştir.

\subsubsection{Karaağaç kazasına iskan edilen konar-göçer topluluklar}

Karaağaç kazasına iskan edilen konar-göçer topluluklar arasında Karakoyunlu, Hayta ve Saçıkaralı aşireti bulunmaktadır. Karakoyunlu aşiretine mensup konar-göçerlerden Karaağaç kaza merkezine 1 çadır/hane de 4 kişi, Yenşehir nahiyesi Kürtler ve Yenice köylerine 1 çadır/hane de 4 kişi, Karaağaç kazası Belceğiz köyüne 1 çadır/hane de 3 kişi, Karaağaç kazası Afşar nahiye merkezine 3 çadır/hane de 16 kişi, Karaağaç kazası Gelendos köyüne 9 çadır/hane de 52 kişi, Karaağaç kazası Karkın köyüne 2 çadır/hane de 10 kişi, Karaağaç kazası Mihail köyüne 2 çadır/ hane de 14 kişi iskan edilmiştir. Hayta aşiretinden 16 çadır/ hane de 83 kişi Karaağaç kazası Armutlu çiftliğine; Saçıkaralı aşiretinden Karaağaç kazası Afşar nahiyesi Yaka köyüne 1 çadır/hane de 3 kişi, Yenice köyüne 1 çadır/hane de 6 kişi, Bağlı köyüne 1 çadır/hane de 8 kişi, Çaltı köyüne 1 çadır/hane de 4 kişi, Götürenin köyüne 1 çadır/hane de 4 kişi iskân edilmiştir.

Karaağaç kaza merkezine iskan edilen 1 çadır/hane de 4 kişiden oluşan Karakoyunlu aşiretine Rum mübadillerinden kalan
37 dönüm arazi, Karaağaç kazası Yenice ve Kürtler köylerine iskan edilen 1 çadır/hane de 4 kişiden oluşan Karakoyunlu aşiretine Rum mübadillerinden kalan 39,5 dönüm arazi, Karaağaç kazası Belceğiz köyüne iskan edilen 1 çadır/hane de 3 kişiden oluşan Karakoyunlu aşiretine Rum mübadillerinden kalan 26,5 dönüm arazi, Karaağaç kazası Afşar nahiyesi merkezine iskan edilen 3 çadır/hane de 16 kişiden oluşan Karakoyunlu aşiretine Rum mübadillerinden kalan 161,5 dönüm arazi, Karaağaç kazası Gelendos köyüne iskan edilen 9 çadır/hane de 52 kişiden oluşan Karakoyunlu aşiretine Rum mübadillerinden kalan 517,5 dönüm arazi, Karaağaç kazası Karkın köyüne iskan edilen 2 çadır/hane de 10 kişiden oluşan Karakoyunlu aşiretine Rum mübadillerinden kalan 98 dönüm arazi, Karaağaç kazası Mihail köyüne iskan edilen 2 çadır/hane de 14 kişiden oluşan Karakoyunlu aşiretine Rum mübadillerinden kalan 145 dönüm arazi, Karaağaç kazası Armudlu çiftliğine iskan edilen 16 çadır/hane de 83 kişiden oluşan Hayta aşiretine Rum mübadillerinden kalan 824 dönüm arazi, Karaağaç kazası Afşar nahiyesi Yaka köyüne iskan edilen 1 çadır/hane de 3 kişiden oluşan Saçıkaralı aşiretine Rum mübadillerinden kalan 34 dönüm arazi, Karaağaç kazası Afşar nahiyesi Yenice köyüne iskan edilen 1 çadır/ hane de 6 kişiden oluşan Saçıkaralı aşiretine Rum mübadillerinden kalan 55 dönüm arazi, Karaağaç kazası Afşar nahiyesi Bağıllı köyüne iskan edilen 1 çadır/hane de 8 kişiden oluşan Saçıkaralı aşiretine Rum mübadillerinden kalan 83,5 dönüm arazi, Karaağaç kazası Afşar nahiyesi Çalt köyüne iskan edilen 1 çadır/hane de 4 kişiden oluşan Saçıkaralı aşiretine Rum mübadillerinden kalan 26 dönüm arazi, Karaağaç kazası Afşar nahiyesi Götüre köyüne iskan edilen 1 çadır/hane de 4 kişiden oluşan Saçıkaralı aşiretine Rum mübadillerinden kalan 44 dönüm arazi, Karaağaç kazası Subaşı mevkiine iskan edilen 30 çadır/hane de 155 kişiden oluşan Saçıkaralı aşiretine 1000 dönüm hali arazi tahsis edilmiştir.

\subsubsection{Isparta kazası kazasına iskan edilen konar-göçer toplu- luklar}

Isparta kazası dahiline Saçıkaralı aşireti iskan edilmiştir. Saçıkaralı aşiretinden Isparta kazası Atabey nahiyesi merkezine 2 çadır/hane de 10 kişi; Isparta kazası Kiçiborlu nahiyesi Eber köyüne 1 çadır/hane de 5 kişi, Isparta kazası Kiçiborlu nahiyesi Senir köyüne 1 çadır/hane de 6 kişi iskan edilmiştir.

Isparta kazası Atabey nahiye merkezine iskan edilen 2 çadır/ hane de 10 kişiden oluşan Saçıkaralı aşiretine Rum mübadillerinden kalan 106 dönüm arazi, Isparta kazası Kiçiborlu nahiyesi Eber köyüne iskan edilen 1 çadır/hane de 5 kişiden oluşan Saçıkaralı aşiretine Rum mübadillerinden kalan 57 dönüm arazi, Isparta kazası Kiçiborlu nahiyesi Senir köyüne iskan edilen 1 çadır/hane de 6 kişiden oluşan Saçıkaralı aşiretine Rum mübadillerinden kalan 59 dönüm arazi tahsis edilmiştir.

\subsubsection{Yalvaç kazasına iskan edilen konar-göçer topluluklar}

Saçıkaralı aşiretine mensup konar-göçer topluluklar Yalvaç'ın muhtelif kesimlerine iskan edilmiştir. Yalvaç kazası Örkenez köyüne 1 çadır/hane de 2 kişi, Hüyüklü köyüne 1 çadır/hane de 3 kişi, Yağcılar köyüne 2 çadır/hane de 6 kişi, Manarga köyüne 1 çadır/hane de 3 kişi, Sücüllü köyüne 2 çadır/hane de 11 kişi, Mısırlı köyüne 1 çadır/hane de 3 kişi, Subaşı mevkiine 30 çadır/hane de 155 kişi iskan edilmiştir. 
Yalvaç kazası Örkenez köyüne iskan edilen 1 çadır/hane de 2 kişiden oluşan Saçıkaralı aşiretine Rum mübadillerinden kalan 20 dönüm arazi, Yalvaç kazası Hüyüklü köyüne iskan edilen 1 çadır/hane de 3 kişiden oluşan Saçıkaralı aşiretine Rum mübadillerinden kalan 25 dönüm arazi, Yalvaç kazası Yağcılar köyüne iskan edilen 2 çadır/hane de 6 kişiden oluşan Saçıkaralı aşiretine Rum mübadillerinden kalan 60 dönüm arazi, Yalvaç kazası Manarga köyüne iskan edilen 1 çadır/hane de 3 kişiden oluşan Saçıkaralı aşiretine Rum mübadillerinden kalan 33 dönüm arazi, Yalvaç kazası Sücüllü köyüne iskan edilen 2 çadır/hane de 11 kişiden oluşan Saçıkaralı aşiretine Rum mübadillerinden kalan 105,3 dönüm arazi, Yalvaç kazası Mısırlı köyüne iskan edilen 1 çadır/hane de 3 kişiden oluşan Saçıkaralı aşiretine Rum mübadillerinden kalan 27 dönüm arazi tahsis edilmiştir.

Aşiret bazında iskan edilen konar-göçerlerin genel toplam nüfusuna bakıldığında şöyle bir dağılım ortaya çıkmaktadır. Eğirdir kazasına Karakoyunlu (200 kişi), Töngüşlü (50 kişi), Eski Yörük (50 kişi), Çakal (108 kişi) ve Honamlı (83 kişi);Uluborlu kazasına Honamlı (464 kişi), Karakoyunlu (342 kişi) ve Saçıkaralı (188 kişi); Karaağaç kazasına Karakoyunlu (103 kişi), Hayta (83 kişi) ve Saçıkaralı (25 kişi); Isparta kazasına Saçıkaralı (21 kişi); Yalvaç kazasına Saçıkaralı (183 kişi) aşiretinin iskanı gerçekleştirilmiştir. 300 kişinin üzerinde konar-göçerin iskan edildiği merkezler Uluborlu kazası Abdülcebbar çiftliğine 658 kişi, Uluborlu kazası Büyük Kayacı köyüne 312 kişi; 150-300 arasında konar-göçerin iskan edildiği merkez Karaağaç kazası Subaşı mevkiine 155 kişi; 26-150 arasında konar-göçerin iskan edildiği merkezler Eğirdir kaza merkezine 108 kişi, Karaağaç kazası Armutlu çiftliğine 83 kişi, Barla nahiye merkezine 83 kişi, Karaağaç kazası Gelendos köyüne 52 kişi, Eğirdir kazası Cebel nahiyesi Bavullu yaylasına 50 kişi ve Zengi yaylasına 50 kişi iskan edildiği görülmektedir (Şekil 2).

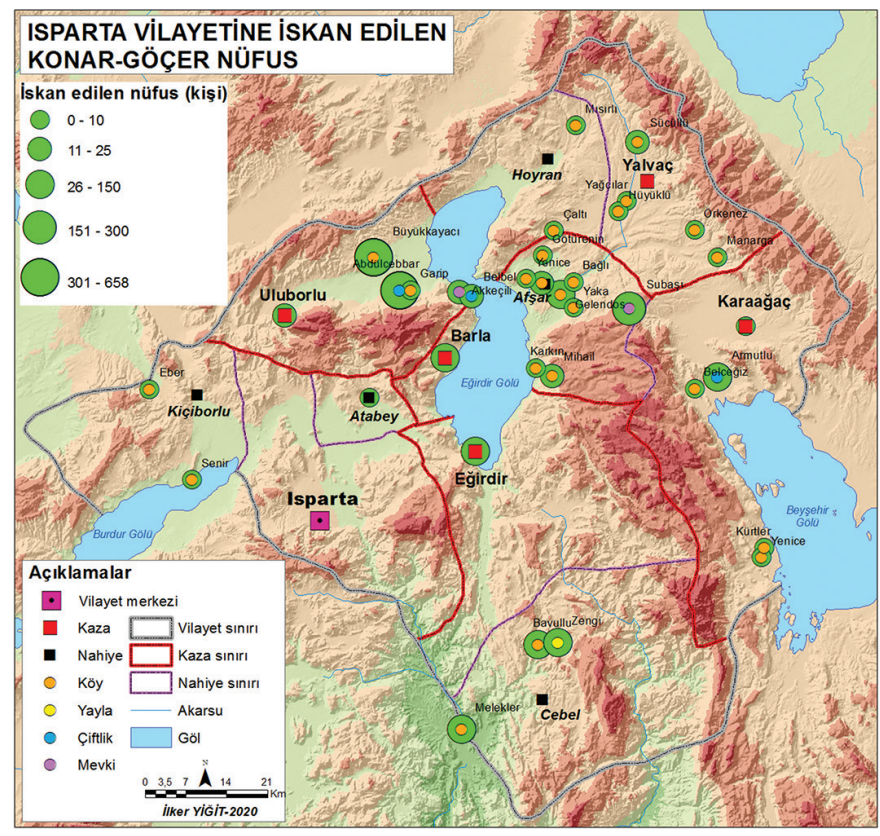

Şekil 2. Isparta Vilayetine İskan Edilen Konar-Göçer Nüfusu

Figure 2. Nomadic Population Settled in Isparta Province

Konar-göçer aşiretler kaza, nahiye, köy gibi daimi iskan merkezlerinin yanında dönemlik yerleşmeler olan yayla ve çiftliklere ve hatta çeşitli mevkilere de iskan edilmişlerdir (Şekil 3).

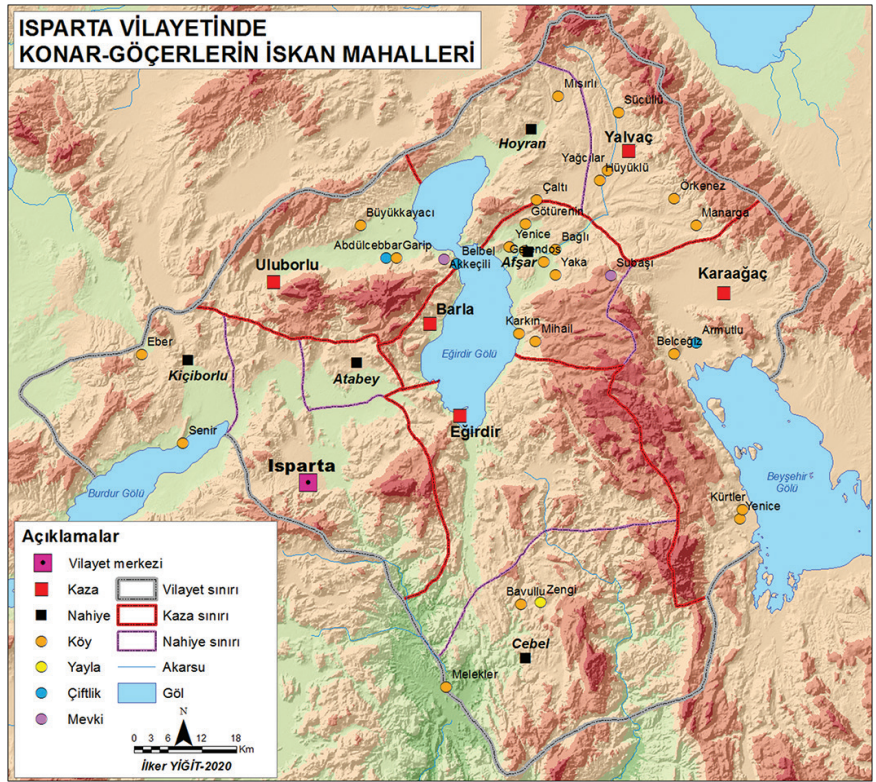

Şekil 3. Isparta Vilayetinde Konar-Göçerlerin İskân Mahalleri Figure 3. Settlement Locus of Nomads in Isparta Province

Zaman içinde dönemlik yerleşmelerin konar-göçerlerin iskan edilmesi neticesinde daimi iskan mahalli olan köylere dönüştüğü anlaşılmaktadır. Hayta aşiretinin yerleştirildiği Karaağaç kazası Armutlu çiftliğinin Armutlu köyüne dönüşmesi bu duruma örnek olarak verilebilir. Ayrıca konar-göçerler daha önce iskan olmayan bazı mevkilere yerleştirilmiş olup zaman içinde buraların da bir iskan merkezi haline gelmesini sağlamışlardır. Bu hususa örnek olarak Eski Yörük aşiretinin iskan edildiği Barla nahiyesi Belbel mevkiinin dönemlik yerleşme olan yaylaya dönüşmesi gösterilebilir.

\section{Sonuç}

- Osmanlı İmparatorluğu zamanında XVII. yüzyılda başlayarak devam eden konar-göçerleri iskan çalışmalarının Cumhuriyet döneminde de devam ettiği anlaşılmaktadır.

- Devletin konar-göçerleri iskan etmesinde çeşitli eşkıyalık faaliyetleri neticesinde çevreye verdikleri zararın yanı sıra rahat bir şekilde ulaşabileceği, kontrol altında tutabileceği yerleşik durumu tercih ettiği söylenilebilir.

- Konar-göçer aşiretlerin iskanı sürecinde devlet, çeşitli komisyonlar kurmak suretiyle yerleşikliğin kalıcı olması için yer ve tarım arazisi tahsis etmeye özen göstermiştir. Isparta vilayetinde bu arazilerin boş ve terk edilmiş olduğu görülmektedir.

- Eğirdir kazası yaylalarında Karakoyunlu, Töngüşlü, Eski Yörük, Çakal, Honamlı; Karaağaç kazası çayır mevkiinde Karakoyunlu; Karaağaç kazası yaylalarında Hayta, Saçıkaralı aşiretleri iskana tabi tutulmuştur. Söz konusu aşiretler Eğirdir, Uluborlu, Karaağaç, Yalvaç ve Isparta kazalarına yerleştirilmeleri gerçekleştirilmiştir.

- Isparta vilayetinde 1925 yılında gerçekleştirilen çalışma neticesinde Eğirdir kazası yaylalarında 201 çadır/hane de 1005 kişi; Karaağaç kazası çayır mevkiinde 80 çadır/hane de 450 kişi, Karaağaç kazası yaylalarında ise 100 çadır/ hane de 500 kişinin iskanı gerçekleştirilmiştir. 
- yapılan çalışma neticesinde Eğirdir kazasına Karakoyunlu (200 kişi), Töngüşlü (50 kişi), Eski Yörük (50 kişi), Çakal (108 kişi) ve Honamlı (83 kişi);Uluborlu kazasına Honamlı (464 kişi), Karakoyunlu (342 kişi) ve Saçıkaralı (188 kişi); Karaağaç kazasına Karakoyunlu (103 kişi), Hayta (83 kişi) ve Saçıkaralı (25 kişi); Isparta kazasına Saçıkaralı (21 kişi); Yalvaç kazasına Saçıkaralı (183 kişi) aşiretleri iskan edilmiştir.

\section{Kaynakça}

a) Arşiv Vesikası: Cumhurbaşkanlığı Devlet Arşivleri Başkanlığı Cumhuriyet Arşivi, 272.0.0.65.6.3.7 (10 K. Evvel 1341/10 Aralık 1925).

\section{b) Araştirma Eserler:}

Ak, M. (2018). Anamas Yaylaları ve Yörükler. Asya Studies-Academic Social Studies/Akademik Sosyal Araşttrmalar 6: 1-6.

Akdemir, S. M. (2008). XVIII. Yüzyılın Illk Yarısında Isparta (Sosyo-Ekonomik ve Kültürel Hayat). Isparta: Isparta Valiliği il Kültür Turizm Müdürlüğü Yayınları.

Aydın, S. ve Yağcı, M. (2013). Sarıkeçililerin “Eşkıyalığı” ve Konya Delibaş İsyanı Üzerine Değinmeler. Kebikeç 35: 59-112.

Babacan, H. ve Temurçin, K. (2013). Türkiye'nin Sıhhı-î lçtimâ-î Coğrafyası:Hamidâbad (Isparta) Sancağı. ısparta: Altınpost Basın.

Böcüzâde Süleyman Sami, (2012). Isparta Tarihi. (Yay. Haz. Hasan Babacan), Isparta: Isparta Valiliği il Kültür Turizm Müdürlüğü Yayınları.

Büyükcan Sayılır, Ş. (2013). Türkiye'de Konar Göçerlerin Sosyo-Tarihsel Yapıları. Hacettepe Üniversitesi Türkiyat Araştırmaları Dergisi. 19: 23-39.

Doğan, M. Said, (2007). Tarihsel Gelişim Sürecinde Yörükler. (Ed. H. Beşirli ve i. Erdal), Anadolu'da Yörükler Tarihi ve Sosyolojik incelemeler. Ankara: Phoenix Yayınevi, s. 133-148.

Egawa H. ve Şahin, i. (2007). Bir Yörük Grubu ve Hayat Tarzı Yağc Bedir Yörükleri. İstanbul: Eren Yayıncılık.

Erdal, i. (2008). Cumhuriyet Döneminde Yörüklerin İskanı Konusu. Osmanlıdan Cumhuriyet'e Yörükler ve Türkmenler. Ankara: Phoenix Yayınevi: 1-13.
Erdal, İ. (2016). Atatürk Dönemi Nüfus Politikasına Göre, Konar-Göçer Aşiretlerin İç İskan Uygulamaları. Çanakkale Araştırmaları Türk Yıllığı 21: 109-121.

Gültekin, H. (Tarihsiz). Osmanlıca Tapu Terimleri Sözlüğüu. (https:// www.tkgm.gov.tr/sites/default/files/icerik/ekleri/osmanlica_ tapu_terimleri_sozlugu.pdf Son Erişim: 14.04.2020)

Gülten, S. (2016). Atayurttan Anayurda Yörükler. Ankara: Gece Kitaplığı.

Gündüz, T. (2002). Konar Göçer. Türkiye Diyanet Vakfi islam Ansiklopedisi. İstanbul: Türkiye Diyanet Vakf Yayınları, 26: 161-163.

Gündüz, T. (2015). Bozkırın Efendileri Türkmenler Üzerine Makaleler. İstanbul: Yeditepe Yayınevi.

Gündüz, T. (2016a). Danişmendli Türkmenleri Kırşehir-Nevşehir-Aydın Hattinda Aşiretler. İstanbul: Yeditepe Yayınevi.

Gündüz, T. (2016b). Anadolu'da Türkmen Aşiretleri. İstanbul: Yeditepe Yayınevi.

Halaçoğlu, Y. (1999). Kolonizasyon ve Şenlendirme. Osmanlı. Ankara: Yeni Türkiye Yayınları, 4: 581-586.

Halaçoğlu, Y. (2014). XIV-XVII. Yüzyıllarda Devlet Teşkilatı ve Sosyal Yapı. Ankara: Türk Tarih Kurumu Yayınları.

İnalcık, H. (2000). Osmanlı Imparatorluğu'nun Ekonomik ve Sosyal Tarihi (C. 1). İstanbul: Eren Yayıncılık.

Kasaba, R. (2012). Bir Konar-Göçer Imparatorluk Osmanlı'da Göçebeler, Göçmenler ve Sığınmacılar. İstanbul: Kitap Yayınevi.

Orhonlu, C. (1987). Osmanlı Imparatorluğunda Aşiretlerin Iskanı. İstanbul: Eren Yayıncılık.

Saydam, A. (1999). Kırım ve Kafkasya'dan Göçler ve Osmanlı İskan Siyaseti (1856-1876). Osmanlı. Ankara: Yeni Türkiye Yayınları 4: 677-685.

Tunçel, H. (2015). Coğrafyanın Yaylacılık Literatürü Üzerine Bir Değerlendirme. (Ed. H. Tunçel) Yayla Kültürü ve Yaylacılık Sempozyumu, Bilecik: Bilecik şeyh Edebali Üniversitesi Yayınları: 5-26.

Yiğit, ì. (2018). XVI.- XX. Yüzyıllarda Anadolu'da Kaybolan Yerleşmeler: Manisa- Konya Örneği. Doktora Tezi. Afyon Kocatepe Üniversitesi. 